\title{
Can COVID-19 Be Transmitted Sexually by Semen?
}

\author{
Ahmed E. Taha ${ }^{1,2}$ iD \\ ${ }^{1}$ Microbiology and Immunology unit, Department of Pathology, College of Medicine, Jouf University, Al-Jouf, \\ Saudi Arabia. \\ ${ }^{2}$ Medical Microbiology and Immunology Department, Faculty of Medicine, Mansoura University, Mansoura, \\ Egypt.
}

\begin{abstract}
Information on the severe acute respiratory syndrome-coronavirus-2 (SARS-CoV-2) has amplified quickly since its spread; however, many issues remain unclear. SARS-CoV-2 is mainly transmitted through respiratory secretions. However, the potential for SARS-CoV-2 sexual transmission by semen is worthy of study. The cell-receptors of SARS-CoV-2, the angiotensin-converting enzyme-2 receptors, are highly expressed in human testis and may enable this virus to cause testicular tissue damage with bad effect on male fertility. SARS-CoV-2 presentation ranges from asymptomatic carriage to acute respiratory distress and fatal pneumonia, and elderly persons with underlying comorbidities usually suffer from a severe clinical picture. Asymptomatic individuals can spread the virus through their respiratory secretions and possibly through sexual transmission. SARS-CoV-2 can persist viable if cryopreserved in semen samples in sperm cryobankes. As far as I know, there is a gap in knowledge about SARSCoV-2 transmission through semen, indicating the need for further research. This review attempts to understand the SARS-CoV-2 sexual transmission by semen. One recent study confirmed the theoretical risk of SARS-CoV-2 transmission by semen, but few studies negate this theory. Given that, an increasing number of asymptomatic and reactivated SARS-CoV-2 cases are being reported, attention to semen safety and SARS-CoV-2 transmission should be considered particularly in high-risk areas, to ensure the safety of male gametes for artificial reproduction and the general public. Avoiding cryopreservation of male gametes, condom use or even abstinence might be of paramount importance for these persons.
\end{abstract}

Keywords: Artificial reproduction, Infection prevention, Pandemic, SARS-CoV-2, Virus

*Correspondence: drahmadmicro@yahoo.com; aeattia@ju.edu.sa

(Received: September 30, 2020; accepted: December 12, 2020)

Abbreviations: ACE2: angiotensin-converting enzyme-2; ART: assisted reproductive technology; COVID-19: coronavirus disease-19; qRT-PCR: quantitative reverse transcription-polymerase chain reaction; SARS-CoV: severe acute respiratory syndromecoronavirus; SARS-CoV-2: severe acute respiratory syndrome-coronavirus-2.

Citation: Taha AE. Can COVID-19 Be Transmitted Sexually by Semen?. J Pure Appl Microbiol. 2020;14(4):2287-2293. doi: 10.22207/JPAM.14.4.06

(C) The Author(s) 2020. Open Access. This article is distributed under the terms of the Creative Commons Attribution 4.0 International License which permits unrestricted use, sharing, distribution, and reproduction in any medium, provided you give appropriate credit to the original author(s) and the source, provide a link to the Creative Commons license, and indicate if changes were made. 


\section{INTRODUCTION}

Sexually transmitted infections are mainly transmitted by sexual contact in humans. Recently, many viruses have been confirmed to be sexually transmitted by semen, although they were previously unknown to be transmitted by sexual contact, for instance, viruses as Zika and Ebola, which were detected in the semen of cases in both the acute and clinical recovery stages of the disease. However, the detection of viral genomes in semen does not confirm that the virus is sexually transmitted; examples of such viruses are certain flaviviruses, paramyxoviruses, and retroviruses. Though, such detection should raise the attention for the need for more infection prevention and control measures ${ }^{1}$.

The pandemic of severe acute respiratory syndrome-coronavirus 2 (SARS-CoV-2), the causative organism of coronavirus disease (COVID-19), has aroused attention worldwide ${ }^{2}$. The SARS-CoV-2 pandemic will result in numerous morbidities, mortalities and major cost impacts. It has been reported that the world lost more than $\$ 280$ billion, and China lost about $\$ 62$ billion in the first quarter of the year $2020^{3}$.

The SARS-CoV-2 clinical presentation ranges from asymptomatic carriage to acute respiratory distress and severe pneumonia. Elderly persons with underlying comorbidities usually suffer from severe clinical picture compared to children and sexually active young adults who present with asymptomatic and mild cases ${ }^{4}$. The number of COVID-19 cases in men is higher than that of women ${ }^{5}$.

Although SARS-CoV-2 is mainly a respiratory virus, some studies have reported that the virus can be found in many human body fluids $s^{5-7}$. The potential for sexual transmission by semen is worthy of study because many COVID-19 cases are asymptomatic or present mild symptoms ${ }^{8-10}$. There is a potential risk for SARS-CoV-2 reactivation as mentioned by Ye et al., who reported that $9 \%$ of patients that were discharged from the hospital had presented SARS-CoV- 2 reactivation confirmed by quantitative reverse transcription- polymerase chain reaction (qRT-PCR) ${ }^{11}$. In addition, Zhang et al. reported a discharged patient, after complete cure from COVID-19, who was retested positive for SARS-CoV-2 by qRT-PCR ${ }^{12}$. The asymptomatic and reactivated cases are dangerous sources for transmission of this fatal virus and represent an infection control challenge, resulting in an increase in the number of cases. To my knowledge, there is wide controversy and big debate about SARSCoV-2 sexual transmission by semen.

\section{Breif Review of SARS-CoV-2 Structure}

A review of the SARS-CoV-2 structure helps in understanding its pathogenesis while infecting the male reproductive tract. SARS-CoV2 has an envelope, a helical nucleocapsid and a single-stranded RNA genome that encodes many proteins including; Spike (S), Membrane (M), Nucleocapsid (N) and Envelope (E) structural proteins $s^{13}$. All these proteins are important for viral replication ${ }^{14}$.

Coronavirus $\mathrm{S}$ protein is a large protein that projects from the envelope as a trimer giving the virus its characteristic crown-like appearance when examined by electron microscopy ${ }^{15}$. Functionally it binds to the specific receptor during the viral entry inside the cell at the beginning of the infection ${ }^{16}$. Furthermore, it determines the host range and tissue tropism and it is a vital immunodominant protein that can induce immune response of the host ${ }^{17}$.

The ectodomain in the $S$ protein of all coronaviruses is divided into two (S1 and S2) domains. The S1 helps in binding to host cell receptor by the receptor-binding domain (RBD) while the $\mathrm{S} 2$ helps in the fusion between the virus and membranes of host cells to allow the viral genome to penetrate the host cells ${ }^{15}$.

The $\mathrm{M}$ proteins are the most abundant proteins present in the viral particle ${ }^{18}$ and play an important role in the viral assembly ${ }^{19}$. The $\mathrm{N}$ proteins enhance the viral transcription and facilitate $M$ protein role during assembly ${ }^{20}$. Although the E proteins are the smallest among the structural proteins ${ }^{21}$, they are important for viral assembly, release, tropism and pathogenesis ${ }^{22}$.

\section{Pathogenesis of SARS-CoV and SARS-CoV-2} Infection of Male Reproductive Tract

Data learnt from SARS-CoV, helps inform knowledge of tissue-specific SARS-CoV-2 pathogenesis. Many receptors for coronaviruses were detected on human cells including angiotensin-converting enzyme-2 (ACE2), Ezrin, CD26 and cyclophilins receptors ${ }^{23,24}$. In SARS-CoV and SARS-CoV-2, the RBD of S1 protein interacts with the ACE2 receptor. Antibodies, vaccines 
or therapeutics targeting this interaction can prevents its entry inside the cell ${ }^{25,26}$.

Douglas et al. ${ }^{27}$ suggested that coronaviruses might impact the men's reproductive tracts either directly (because ACE2 receptors are expressed selectively by the Leydig cells of adult testes) or immunologically after inoculation of the viral RNA within the testicular tissue. It was reported in 2005 that postmortem testicular tissue focal atrophy was detected in eight SARSCoV deceased patients, but the viral RNA was not detected in testicular biopsy ${ }^{28}$. Furthermore, in $2006 \mathrm{Xu}$ et al. ${ }^{29}$ reported sever orchitis cases caused by SARS-CoV with massive germ cell destruction, immunoglobulin $\mathrm{G}$ precipitation and leukocyte infiltration in testicular tissues.

The SARS-CoV-2 infection of human male reproductive tract needs more clarification. During the current COVID-19 pandemic, it was reported that the cell-receptors of SARS-CoV-2 (ACE2 receptors) are highly expressed in human testis and could enable the virus to cause testicular tissue damage with bad effects on men's fertility all over the world. SARS-CoV-2 may be presented by orchitis, consequently, it is reasonable to consider the possibility of its transmission by semen. Additional studies on male reproductive tract infection by coronaviruses are necessary, especially among recovered person $\mathrm{s}^{30}$.

Effects of SARS-CoV-2 ON Human Male Gametes Information on SARS-CoV-2 has amplified quickly since its spread; however, many issues remain unclear regarding its impact on male reproduction. ACE2 receptors are much more expressed in the reproductive systems of males than females. As discussed above, the SARSCoV-2 virus attaches to the ACE2 receptors within the adult Leydig cells in the testis to enter inside the cells. It was reported that ACE2 plays an important role in spermatogenesis. Therefore, spermatogenesis could be affected ${ }^{31,32}$. Furthermore, fever can affect spermatogenesis. Sperm count and motility may be decreased for 72-90 days following fever ${ }^{33,34}$.

We must deal with gametes of patients infected by some other viral diseases, such as hepatitis and human immunodeficiency virus, with special care to reduce exposure of noninfected partners and cross-contamination of within the assisted reproductive technology
(ART) laboratories ${ }^{35}$. The Society for Assisted Reproductive Technology (SART) and the American Society for Reproductive Medicine (ASRM) have warned prospective parents, gamete donors, ART patients and gestational carriers from pregnancy or participation in fertility programs in case of fulfilling the diagnostic criteria for COVID- $19^{36}$. The Center for Diseases Control and Prevention (CDC) has not excluded the possibility of SARSCoV-2 transmission by non-respiratory body fluids, including semen, from infected persons ${ }^{37}$.

La Marca et al..$^{38}$ reported that Italian authorities are mandating interviewing of all gamete donors regarding COVID-19 respiratory symptoms and/or their recent travel history to high-risk places. If COVID-19 respiratory symptoms are presented, they should postpone gamete donation for two weeks after clearance of symptoms and/or returning from a high-risk place.

Most viruses can be stored dried at ultralow temperatures in suitable protein concentrations ${ }^{39}$. Both SARS-CoV-2 and influenza viruses are RNA enveloped viruses. Cryopreserved influenza viruses can persist infectious even after 40 years $^{40}$. Similarly, SARS-CoV-2 could persist viable if cryopreserved in semen samples in sperm cryobankes $^{41}$.

Interestingly, a recent study reported the importance of a transmembrane serine protease 2 (TMPRSS2) protein during the viruscell fusion process ${ }^{42}$. Nevertheless, this protein is rarely expressed within tissues of the testis ${ }^{43}$. Consequently, vulnerability of the testis to SARSCoV-2 may be doubtful.

In this context, further investigations are necessary to pledge the safety of male gametes and ART. Therefore, the present review aimed to study the gap in knowledge about SARSCoV-2 transmission through semen until August 2020. PubMed and other related databases were reviewed using the keywords (ACE2, Artificial reproduction, COVID-19, SARS-CoV-2, semen, sexual). Original articles, confirming or excluding presence of SARS-CoV- 2 in semen, were included in this review. This review is highlighting the possibility of semen to be a vehicle for transmission of SARS-CoV-2. Some recent studies negate the presence of SARS-CoV-2 in semen ${ }^{44-52}$ and only one study proves its presence ${ }^{53}$. 


\section{Reports Excluding Possibility of SARS-CoV-2 Transmission by Semen}

Song et al. ${ }^{44}$ reported that SARS-CoV-2 was not detected by qRT-PCR in testicular samples of one patient who died during the acute phase of COVID-19 and in semen samples collected from 12 infected men at the recovery phase (the period after two consecutive negative respiratory qRT-PCR tests or a significant resolution on chest CT scans with much many symptoms). They excluded possibility of sexually transmitted SARSCoV-2 by semen. Furthermore, they excluded the possibility of SARS-CoV-2 infecting the male genital tract. Limitations of their study were the small number of cases that were tested and the insubstantial number of semen samples that could be collected from the cases while they were sick. They recommended that more patients, more semen samples, and more pathological and physiological examinations of the male genital system are needed to confirm their findings.

Similarly, Paoli et al. ${ }^{45}$ reported that SARS-CoV-2 was not detected by qRT-PCR in a semen sample collected from a 31-year-old man (voluntary participant) who was found positive for SARS-CoV-2 in a pharyngeal swab eight days before collecting the semen sample. The patient's symptoms were mild fever, anosmia, and myalgia. The limitation of their study was that it involved only one case and one semen sample that was collected on the $8^{\text {th }}$ day after the first positive pharyngeal swab, this was obligatory owing to poor health condition of that patient during the peak of the disease. They formulated two hypotheses: the first is that SARS-CoV-2 was present in semen, at the peak of the infection, but cleared with the progressive clinical recovery of the patient during the eight days; the second is that SARS-CoV-2 was never present in the semen at the time of testing. Furthermore, they recommended that more semen samples (if possible) should be collected from more patients with more severe symptoms, especially during the acute phase when virus shedding can be detected in the semen.

Furthermore, Pan et al. ${ }^{46}$ collected a single semen sample from 34 adult Chinese males. The cases were diagnosed with SARS-CoV- 2 by confirmatory qRT-PCR from pharyngeal swabs. Semen was collected after a median of 31 days from COVID-19 confirmation. SARS-CoV-2 was not detected in the semen. Pan and his team concluded that although they did not detect the virus in the tested recovering patients, they cannot definitively exclude its presence in the semen during an acute SARS-CoV-2 infection with severe symptoms. In addition, the study reported presence of orchialgia in some tested cases that indicate possibility of testicular damage. Moreover, they recommended the need to further research for understanding the SARS-CoV-2 long-term effect on male fertility, reproductive and testicular endocrine functions.

In Renmin hospital of Wuhan university of China, Ning et al. ${ }^{47}$ excluded the presence of SARS-CoV- 2 in semen of 112 COVID-19 confirmed male patients. All semen samples were negative for the ORF1ab and N genes. Orchidoptosis was detected in three severe COVID-19 patients (2.7\%). Another report from China negated the presence of SARS-CoV-2 RNA in semen of tested 23 men (11 patients were tested negative and the other 12 patients were still positive in sputum and fecal samples) ${ }^{48}$.

In Germany, Holtmann and her colleagues ${ }^{49}$ performed a pilot cohort study during which they obtained 18 semen samples from recovered men (8-54 days after clearance of symptoms), two semen samples from active COVID-19 patients and 14 semen samples from control persons. No SARS-CoV-2 RNA was detected in any semen sample by RT-PCR. They concluded that mild SARS-CoV-2 infection is doubtful to affect the testis, whereas moderate infection could impair the semen parameters.

Similar results were reported from USA by Rawlings et al. ${ }^{50}$ when SARS-CoV-2 RNA was not detected in semen of six COVID-19 male patients (6-17 days after the symptoms onset) in spite of associate shedding in oral secretions. Furthermore, the results of a Turkish study supported the believe that sexual transmission of SARS-CoV-2 through semen does not has a vital role after they did not detect its SARS-CoV-2 RNA in semen of 16 patients although all the semen samples were collected during the acute phase of the disease while the tests of nasopharyngeal swabs were positive ${ }^{51}$.

In Italy, Pavone et al. ${ }^{52}$ reported that no evidence of SARS-CoV-2 in semen of nine Italian males recovering from mild COVID-19 in spite of prolonged positivity of nasopharyngeal swabs. Despite the limited size of this study, 
they outweighed low probability of SARS-CoV-2 sexual transmission by men recovering from mild symptoms. However, they did not rule out the presence of SARSCoV-2 in the semen of sever acute cases. They recommended larger scale studies to analyze serial samples collected from the start of symptoms till complete recovery of the disease.

Reports Approving Possibility of SARS-CoV-2 Transmission by Semen

Surprisingly, a recent study by Li et al. ${ }^{53}$ confirmed the presence of SARS-CoV- 2 in semen samples collected from 6 patients by qRT-PCR. The study included 38 participants, of which 15 were in the acute phase of the disease and 23 were in the clinical recovery phase. Among the 6 positive patients, 4 were in the acute phase and 2 in the recovery phase, which is predominantly noteworthy. They outweighed that SARS-CoV-2 could be seeded and persist in the testes and semen even after clinical recovery due to inflammation (systemic and local), imperfect blood-testes/deferens/epididymis barriers and the privileged immunity of testes. This study was limited by the small sample size and the short follow-up period. The study recommended that further researches should focus on SARS-CoV-2 shedding, survival time, and infectious dose in the semen.

\section{CONCLUSION}

In conclusion, there is a gap in knowledge about SARS-CoV-2 in the semen, which shows that further researches are required. Given that, an increasing number of asymptomatic and reactivated SARS-CoV-2 cases are being reported, attention to semen safety and SARS-CoV-2 transmission should be considered particularly in high-risk areas to ensure the safety of the general public and cryopreserved male gametes for artificial reproduction. More attention should be considered when dealing with patients suffering from COVID-19 severe clinical picture. This study might provide new information about COVID-19 prevention and control.

\section{Recommendations}

While we do not currently have all the answers regarding possibility of SARS-CoV-2 transmission by semen, I suggest that SARS-CoV-2 sexual transmission should be considered during prevention and control of this fatal virus depending on the findings suggesting that it could be found in the semen of recovering patients who might be young and sexually active. Furthermore, this may happen in patients during the incubation period or with no or mild symptoms who can practice sex or cryopreserve their gametes. When dealing with a couple in which the man has been diagnosed with COVID-19, avoiding cryopreservation of male gametes, condom use or even abstinence might be of paramount importance for these persons.

\section{ACKNOWLEDGMENTS}

None.

\section{FUNDING}

None.

\section{DATA AVAILABILITY}

All datasets generated or analyzed during this study are included in the manuscript.

\section{ETHICS STATEMENT}

This article does not contain any studies with human participants or animals performed by the author.

\section{REFERENCES}

1. Feldmann $\mathrm{H}$. Virus in semen and the risk of sexual transmission. N Engl J Med. 2018:378(15):1440-1441. doi: 10.1056/NEJMe1803212

2. Taha AE. The Severe Acute Respiratory Syndrome Coronavirus-2 Pandemic: An Overview to Control Human-wildlife and Human-human Interactions. J Pure App/ Microbiol. 2020;14(2):1095-1098. doi: 10.22207/ JPAM.14.2.02

3. Ayittey FK, Ayittey MK, Chiwero NB, Kamasah JS, Dzuvor C. Economic impacts of Wuhan $2019 \mathrm{nCoV}$ on China and the world. J Med Virol. 2020;92(5):473-475. doi: 10.1002/jmv.25706

4. Huang C, Wang Y, Li X, et al. Clinical features of patients infected with 2019 novel coronavirus in Wuhan, China. The Lancet. 2020;395(10223):497-506. doi: 10.1016/ S0140-6736(20)30183-5

5. Guan WJ, Zhong N-S, et al. Clinical characteristics of coronavirus disease 2019 in China. N Engl J Med. 2020: 382:1708-1720. doi: 10.1056/NEJMoa2002032

6. Xia J, Tong J, Liu M, Shen Y, Guo D. Evaluation of coronavirus in tears and conjunctival secretions of patients with SARS-CoV-2 infection. J Med Virol. 2020;92(6):589-594. doi: 10.1002/jmv.25725

7. Chen L, Wang S, et al. Detection of 2019-nCoV in Saliva and Characterization of Oral Symptoms in COVID-19 Patients. Report No.: ID 3557140.

8. Bai Y, Yao L, Wei T, et al. Presumed asymptomatic carrier 
transmission of COVID-19. JAMA. 2020;323(14):14061407. doi: $10.1001 /$ jama.2020.2565

9. Chang D, Xu H, Rebaza A, Sharma L, Dela-Cruz CS Protecting health-care workers from subclinical coronavirus infection. Lancet Respir Med. 2020;8(3):e13. doi: 10.1016/S2213-2600(20)30066-7

10. The Novel Coronavirus Pneumonia Emergency Response Epidemiology Team: The epidemiological characteristics of an outbreak of 2019 novel coronavirus disease (COVID-19)-China. China CDC Weekly. 2020;2(8):113-122.

11. Ye G, Pan Z, Pan Y, et al. Clinical characteristics of severe acute respiratory syndrome coronavirus 2 reactivation. J Infect. 2020;80(5):e14-e17. doi: 10.1016/j.jinf.2020.03.001

12. Zhang J-F, Yan K, Ye H-H, Lin J, Zheng J-J, Cai T. SARSCoV-2 turned positive in a discharged patient with COVID-19 arouses concern regarding the present standard for discharge. Int J Infect Dis. 2020;97:212214. doi: 10.1016/j.ijid.2020.03.007

13. Fehr AR, Perlman S. Coronaviruses: an overview of their replication and pathogenesis. Methods Mol Biol. 2015;1282:1-23. doi: 10.1007/978-1-4939-2438-7_1

14. Chen Y, Liu Q, Guo D. Emerging coronaviruses: genome structure, replication, and pathogenesis. J Med Virol. 2020;92(4):418-423. doi: 10.1002/jmv.25681

15. Belouzard S, Millet JK, Licitra BN, Whittaker GR. Mechanisms of coronavirus cell entry mediated by the viral spike protein. Viruses. 2012;4(6):1011-1033. doi: 10.3390/v4061011

16. Beniac DR, Andonov A, Grudeski E, Booth TF. Architecture of the SARS coronavirus prefusion spike. Nat Struct Mol Bio. 2006;13(8):751-752. doi: 10.1038/ nsmb1123

17. Li F. Structure, Function, and Evolution of Coronavirus Spike Proteins. Annu Rev Virol. 2016;3(1):237-261. doi: 10.1146/annurev-virology-110615-042301

18. Neuman BW, Kiss G, Kunding AH, et al. A structural analysis of $M$ protein in coronavirus assembly and morphology. J Struct Biol. 2011;174(1):11-22. doi: 10.1016/j.jsb.2010.11.021

19. Nal B, Chan C, Kien F, et al. Differential maturation and subcellular localization of severe acute respiratory syndrome coronavirus surface proteins $\mathrm{S}, \mathrm{M}$ and $\mathrm{E}$. J Gen Virol. 2005;86(5):1423-1434. doi: 10.1099/ vir.0.80671-0

20. Sheikh A, Al-Taher A, Al-Nazawi M, Al-Mubarak $\mathrm{Al}$, Kandeel $\mathrm{M}$. Analysis of preferred codon usage in the coronavirus $\mathrm{N}$ genes and their implications for genome evolution and vaccine design. $J$ Virol Methods. 2020;277:113806. doi: 10.1016/j. jviromet.2019.113806

21. Schoeman D, Fielding BC. Coronavirus envelope protein: current knowledge. Virol J. 2019;16(1):69. doi: 10.1186/s12985-019-1182-0

22. Nieto-Torres JL, DeDiego ML, Verdia-Baguena $C$, et al. Severe acute respiratory syndrome coronavirus envelope protein ion channel activity promotes virus fitness and pathogenesis. PLOS Pathog. 2014;10(5):e1004077. doi: 10.1371/journal. ppat.1004077

23. Millet JK, Ken F, Cheung C-Y, et al. Ezrin interacts with the
SARS coronavirus Spike protein and restrains infection at the entry stage. PLOS ONE. 2012;7(11):e49566. doi: 10.1371/journal.pone.0049566

24. Song W, Gui M, Wang X, Xiang Y. Cryo-EM structure of the SARS coronavirus spike glycoprotein in complex with its host cell receptor ACE2. PLOS Pathog. 2018;14(8):e1007236. doi: 10.1371/journal. ppat.1007236

25. Raj VS, Mau H, Smits SL, et al. Dipeptidyl peptidase 4 is a functional receptor for the emerging human coronavirus-EMC. Nature. 2013;495:251-254. doi: 10.1038/nature12005

26. Song $Z, X u Y, B a o L$, et al. From SARS to MERS, thrusting coronaviruses into the spotlight. Viruses. 2019;11(1):59. doi: 10.3390/v11010059

27. Douglas GC, O'Bryan MK, Hedger MP, et al. The novel angiotensin-converting enzyme (ACE) homolog, ACE2, is selectively expressed by adult Leydig cells of the testis. Endocrinology. 2004;145(10):4703-4711. doi: 10.1210/en.2004-0443

28. Gu J, Gong E, Zhang B, et al. Multiple organ infection and the pathogenesis of SARS. J Exp Med. 2005;202(3):415-424. doi: 10.1084/jem.20050828

29. Xu J, Qi L, Chi X, et al. Orchitis: a complication of severe acute respiratory syndrome (SARS). Biol Reprod. 2006;74(2):410-416. doi: 10.1095/ biolreprod.105.044776

30. Fan C, Li K, Ding Y, Lu LW, Wang J. ACE2 expression in kidney and testis may cause kidney and testis damage after 2019-nCoV infection. medRxiv. 2020. doi: 10.1101/2020.02.12.20022418

31. Pan P-P, Zhan Q-T, Le F, Zheng Y-M, Jin F. Angiotensinconverting enzymes play a dominant role in fertility. Int J Mol Sci. 2013;14(10):21071-21086. doi: 10.3390/ ijms141021071

32. Robinson JL, Kocabas, Wang $\mathrm{H}$, et al. An atlas of human metabolism. Sci Signal. 2020;13(624):eaaz1482. doi: 10.1126/scisignal.aaz1482

33. Carlsen E, Andersson AM, Petersen JH, Skakkebaek NE. History of febrile illness and variation in semen quality. Hum Reprod. 2003;18(10):2089-2092. doi: 10.1093/ humrep/deg 412

34. Jung A, Schuppe HC. Influence of genital heat stress on semen quality in humans. Andrologia. 2007;39(6):203215. doi: 10.1111/j.1439-0272.2007.00794.x

35. Practice Committee of American Society for Reproductive Medicine. Recommendations for reducing the risk of viral transmission during fertility treatment with the use of autologous gametes: a committee opinion. Fertil Steril. 2013;99(2):340-346. doi: 10.1016/j.fertnstert.2012.08.028

36. Society for Assisted Reproductive Tecnology (SART), (2020). SART and ASRM issue advice for infertility patients concerning the novel coronavirus (COVID-19). [Accessed 27 May 2020]. https://www.sart.org/ news-and-publications/news-and-research/pressreleases-and-bulletins/sart-and-asrm-issue-advice-forinfertility-patients-concerning-the-novel-coronaviruscovid-19/

37. Center for Diseases Control and Prevention (CDC), (2020) Clinical questions about COVID-19. [Accessed 27 May 2020]. https://www.cdc.gov/coronavirus/2019- 
ncov/hcp/faq. Html.

38. La Marca A, Niederberger C, Pellicer A, Nelson SM. COVID-19: lessons from the Italian reproductive medical experience. Fertil Steril. 2020;113(5):920-922. doi: 10.1016/j.fertnstert.2020.03.021

39. Gould EA. Methods for long-term virus preservation. Mol Biotechnol. 1999;13(1):57-66. doi: 10.1385/ MB:13:1:57

40. Merrill DR, Wade CD, Fahnestock P, Baker RO. Longterm and short-term stability of viruses depend on storage temperature and preservation method. Beiresources poster. 2018. [Accessed 27 May 2020]. https://www.beiresources.org/Portals/2/PDFS/LongTerm\%20and\%20Short-Term\%20Stability\%20of\%20 Viruses.pdf

41. Yakass MB, Woodward B. COVID-19: should we continue to cryopreserve sperm during the pandemic? Reprod Biomed Online. 2020;40(6):905. doi: 10.1016/j. rbmo.2020.04.004

42. Hoffmann M, Kleine-Weber H, Schroeder S, et al. SARSCoV-2 Cell Entry Depends on ACE2 and TMPRSS2 and Is Blocked by a Clinically Proven Protease Inhibitor. Cell. 2020;181(2): 271-280. doi: 10.1016/j.cell.2020.02.052

43. Stanley KE, Thomas E, Leaver M, Wells D. Coronavirus disease-19 and fertility: viral host entry protein expression in male and female reproductive tissues. Fertil Steril. 2020;114(1):33-43. doi: 10.1016/j. fertnstert.2020.05.001

44. Song C, Wang Y, Li W, et al. Absence of 2019 novel coronavirus in semen and testes of COVID-19 patients. Biol Reprod. 2020;103(1): 4-6. doi: 10.1093/biolre/ ioaa050

45. Paoli D, Pallotti F, Colangelo S, et al. Study of SARSCoV-2 in semen and urine samples of a volunteer with positive naso-pharyngeal swab. J Endocrinol Invest. 2020:43(12):1819-1822. doi: 10.1007/s40618-020-
01261-1

46. Pan F, Hotaling JM, et al. No evidence of severe acute respiratory syndrome-coronavirus 2 in semen of males recovering from coronavirus disease 2019. Fertil Steril. 2020;113(6):1135-1139. doi: 10.1016/j. fertnstert.2020.04.024

47. Ning J, Cheng F, et al. Effects of 2019 novel coronavirus on male reproductive system: a retrospective study. Preprints. 2020. doi: 10.20944/preprints202004.0280. v1

48. Guo L, Yuan M, et al. Absence of SARS-CoV- 2 in semen of a COVID-19 patient cohort. Andrology. 2020. doi: 10.1111/andr.12848

49. Holtmann N, Bielfeld AP, et al. Assessment of SARS-CoV-2 in human semen-a cohort study. Fertil Steril. 2020:114(2):233-238. doi: 10.1016/j. fertnstert.2020.05.028

50. Rawlings SA, Ignacio C, Porrachia M, Du P, Smith DM, Chaillon A. No Evidence of SARS-CoV-2 Seminal Shedding Despite SARS-CoV-2 Persistence in the Upper Respiratory Tract. Open Forum Infectious Diseases. 2020;7(8):ofaa325. doi: 10.1093/ofid/ofaa325

51. Kayaaslan B, Guner R, et al. Investigation of SARS-CoV-2 in Semen of Patients in the Acute Stage of COVID-19 Infection. Urol Int. 2020;104(9-10):678-683. doi: 10.1159/000510531

52. Pavone $\mathrm{C}$, Bonura $\mathrm{F}$, et al. Italian males recovering from mild COVID-19 show no evidence of SARS-CoV-2 in semen despite prolonged nasopharyngeal swab positivity. Int J Impot Res. 2020;32(5):560-562. doi: 10.1038/s41443-020-00344-0

53. Li D, Jin M, Bao P, Zhao W, Zhang S. Clinical Characteristics and Results of Semen Tests Among Men With Coronavirus Disease 2019. JAMA Network Open. 2020;3(5):e208292. doi: 10.1001/ jamanetworkopen.2020.8292 